\title{
Research on the Impact of Innovative City Construction on Financial Development: Evidence from China
}

\author{
Zhaoyang Zhao $\mathbb{D}^{1},{ }^{1}$ Yanhong Zheng $\mathbb{D}^{2},{ }^{2}$ Yuhong Chen $\mathbb{D}^{1},{ }^{1}$ Chong Ye $\mathbb{D}^{1},{ }^{1}$ and Zeyu He ${ }^{3}{ }^{3}$ \\ ${ }^{1}$ School of Economics and Management, Fuzhou University, Fuzhou 350108, China \\ ${ }^{2}$ School of Advanced Manufacturing, Fuzhou University, Jinjiang 362251, China \\ ${ }^{3}$ The Faculty of Business and Management, UCSI University, Kuala Lumpur 500000, Malaysia
}

Correspondence should be addressed to Zeyu He; 1002164165@ucsiuniversity.edu.my

Received 30 September 2021; Revised 6 November 2021; Accepted 10 November 2021; Published 23 November 2021

Academic Editor: Daqing Gong

Copyright (c) 2021 Zhaoyang Zhao et al. This is an open access article distributed under the Creative Commons Attribution License, which permits unrestricted use, distribution, and reproduction in any medium, provided the original work is properly cited.

\begin{abstract}
Science and technology innovation is the new driving force of urban development, and it is an important vehicle to promote financial development. Innovative city attaches importance to the driving role of science and technology innovation capacity on industry development in the construction process, which will drive the development of the city's financial industry. This article takes China's innovative city pilot policy as a quasinatural experiment and uses the panel data of 235 prefecture-level cities in China from 2005 to 2017 to construct a difference-in-differences model (DID) to investigate the net effect and mechanism of the policy implementation on the financial development level of pilot cities. The results show the following: (1) the construction of innovative cities has significantly improved the financial development level of pilot cities, and the conclusion is still valid through the robustness test; (2) the financial development level promotion effect of innovative city construction has regional heterogeneity, and the financial development level promotion effect of central cities is more significant; (3) the construction of innovative cities can improve the financial development level of pilot cities by improving the intermediary effect of scientific and technological talents gathering and industrial structure upgrading.
\end{abstract}

\section{Introduction}

In the process of economic globalization with increasingly fierce international competition, many countries take strengthening the national innovation system as a national strategy and the investment in scientific and technological innovation as a strategic investment so as to enhance the national innovation ability and enhance the international competitiveness. The work report of the Chinese Central Government in 2021 points out that one of the main goals and major tasks of China's economic and social development during the "14th Five-Year Plan Period" is to uphold innovation-driven development, continue to adhere to the core position of innovation in China's overall modernization drive, and maintain sustained and healthy economic development. At present, the world is undergoing a great change in the past century. The spread of COVID-19 has also hindered the mechanism of city mobility and financial synergy. As the space carrier of innovation activities, cities gather innovation resources and innovation elements, including high-quality talents and abundant $R \& D$ capital, which is very important to achieve high-quality financial development. Since 2008, China has carried out a number of innovative city pilot projects, including 78 prefecture-level cities such as Shenzhen and Beijing, aiming to create innovation leading highland and realize innovation leading development strategy. In this context, with the promotion and deepening of innovative city construction, has the pilot policy achieved the desired effect? Has the pilot policy improved the level of financial development? Does the pilot policy have heterogeneity of policy effect due to different regions? And what mechanism can promote the development of urban finance?

The marginal contributions of this article are mainly in the following three aspects: (1) In the content of the study, this article combines the study of innovative city 
construction and financial industry development. This article discusses in depth the impact of innovative city construction on the financial industry development and conducts an empirical analysis based on the city level. This not only enriches the research on innovative city construction, but also expands the existing academic literature in the field of financial development influencing factors. (2) In terms of research methods, since the selection of innovative city pilot is not a random selection process, this article takes innovative city pilot policy as a quasinatural experiment and selects difference-in-differences method (hereinafter referred to as DID) to conduct an empirical study, which can effectively overcome the endogeneity problem caused by omitted variables and ensure the reliability of the research findings. (3) Finally, this article uses the intermediary effect model to analyze the mechanism of the role of innovative city construction on the financial development level. The results of the analysis show that the innovative city construction mainly improves the financial industry development by increasing the concentration of scientific and technological talents in the pilot cities and by promoting the advanced development of the city's industry structure, which provides a theoretical and policy basis for our government to further summarize the pilot experience and continue to promote the construction of innovative cities and highquality financial development.

\section{Literature Review and Hypothesis Proposed}

The research of this article is closely related to the following three types of literature: (1) research on the influencing factors of financial development; (2) research on the effect of innovative city construction; and (3) research on the mechanism of innovative city construction to promote financial development.

\subsection{Research on the Influencing Factors of Financial} Development. Previous studies show that the academic research perspectives on the influencing factors of financial development can be summarized as economic, political, and technological perspectives.

From the perspective of economy, the living standards of local people have a significant positive impact on financial development, and financial activities should be based on the regions with more developed economy and higher level of opening to the outside world. The study of Zhou et al. shows that there is a large rural population in the central region of China, the credit environment is not well secured, and there are certain risks in the construction of the financial system [1]. In addition, some scholars measure the difference of rural financial development in China, and the results show that factors such as per capita net income have a positive impact on the difference of financial development, while factors such as per capita freight volume and urbanization level have a negative impact.

From the political perspective, with the transformation and upgrading of China's economy, the positive role of the rule of law and local governments in financial development is gradually emerging. Bordo and Rousseau show that the higher the level of rule of law and government efficiency, the more developed the financial market [2]. Zeng et al. use panel data from 2000 to 2015 for 2873 counties (districts) and 289 prefecture-level cities in China and performs quantile regression analysis. Quantile regression analysis reveals that in highly innovative cities, local governments are more interested in leveraging regional absorptive capacity to trigger technology spillovers from industries such as the financial industry. At the same time, because of the relatively high level of $R \& D$ contributions in innovative cities, governments are better able to leverage $R \& D$ activities to develop their comparative advantage in regional innovation [3].

From the perspective of science and technology, the rise of information technology has a wide impact on finance. Ye et al. use the data of 226 prefecture-level cities from 2006 to 2017 to construct a difference-in-differences model (DID) to study smart city construction in China. The results of the study show that the digital and intelligent transformation of the industry significantly improved the quality of the city in attracting foreign investment and promote the high-quality development of industries such as the city's financial industry [4]. Alshubiri et al. show that information technology also helps to improve the efficiency of electronic transactions and promote e-finance development through business operations on the Internet. In terms of the market, with the popularity of electronic payment methods, healthy competition among financial institutions can provide better services to consumers [5].

\subsection{Research on the Effect of Innovative City Construction.} At present, scholars mostly focus on the relationship between innovative city construction and high-quality economic development. Innovative city construction is based on urban elements, emphasizes technological innovation, and optimizes the industry structure through technological upgrading of investment and financing. Zhang takes the innovative city construction as a quasinatural experiment and uses the DID model and PSM-DID model to make an empirical study. The results show that innovative city construction improves the concentration level of scientific and technological talent through the level of urban human capital and the level of industrial structure and reflects heterogeneity in the time dimension [6]. Hospers shows that innovative cities characterized by well-developed scientific and technological capabilities and service institutions are able to gather a large number of diversified high-level innovative talents, attract excellent research institutions and organizations, and establish world-renowned innovation platforms and spatial carriers [7]. In addition, in the process of building an innovative city, the government has set up a special leadership body, carried out multilevel innovation coordination to develop a sound innovation promotion policy, and used national-level laws and regulations to support the development of private innovation organizations [8]. Zhang et al. take the Yangtze River Delta region as the research object; an empirical study was conducted 
through DEA model, and the results of the study show innovative city construction by encouraging universities and research institutions to actively carry out innovative activities. It not only realizes knowledge sharing and innovation, but also effectively applies knowledge results to all aspects of industry innovation activities through the process of knowledge flow, thus promoting the development of industry [9].

\subsection{Mechanism Analysis of Financial Development Promoted} by Innovative City Construction. Theoretically speaking, the government's innovative city construction will have a significant role in promoting the city. The reasons mainly include the following four aspects.

First, innovative city construction enhances industry production efficiency and optimizes industry allocation ratio, which can effectively promote the development of advanced urban industrial structure and enhance financial development level. Guo and Wang point out that for innovative pilot cities, local governments reduce the cost of enterprise $\mathrm{R} \& \mathrm{D}$ and promote high-tech innovation by issuing subsidy policies and setting up special funds and other incentive means, which promotes the upgrading of industrial structure to a certain extent and leads to financial agglomeration and financial development through innovation incentive effect and scale economy effect [10].

Secondly, innovative cities construction can enhance financial development by triggering a concentration of talents. As a kind of city brand, innovative cities attract talents through the enactment of various policies and their own innovative potential, thus creating a concentration of talents [7]. Meanwhile, the study of Aibai et al. shows that talent is one of the core factors affecting the rapid development of the financial industry. The radiation effect formed by the concentration of talents also provides support and guarantee for the development of the financial industry. Therefore, building an innovative city can promote financial development through the talent pooling path [11].

Again, innovative city construction can enhance financial development by improving the quality of foreign investment. The quality of foreign investment relies on the support of regional innovation environment, and the high-quality development of finance is also inseparable from the inflow of high-quality foreign investment. The increase of high-quality foreign investment inflow can optimize the financial scale, financial structure, and financial efficiency and promote the development of financial industry.

Finally, Li et al. showed that the construction of innovative cities has led the government to provide support to innovation activities through innovation institutional reforms and the implementation of financial and tax incentives and other policies to improve the efficiency of the use of innovation factors in the city and ultimately enhance the development of sectors, such as finance [12].

Based on the above analysis, it can be seen that innovative city construction enhances financial development through the following four aspects: promoting the development of advanced industrial structure, triggering the gathering of talents, improving the quality of foreign investment, and strengthening government governance capacity. The mechanism of action is shown in Figure 1.

Through combing the literature, it can be found that prior studies have summarized the influencing factors of financial development in three dimensions: economic, political, and technological, and have analyzed the policy effects and heterogeneity of innovative city construction to a certain extent, but the prior studies have not addressed the relationship between innovative city construction and financial development. For China, it is important to explore whether the construction of innovative cities can enhance the level of financial development and to analyze the path of enhancement, in order to sustain the construction of innovative cities and promote high-quality economic development in China. Therefore, this article proposes the following hypotheses, taking the pilot policy of innovative cities as the research object and combining with prior research.

H1. Innovative city construction can enhance financial development

H2. The impact of innovative city construction on the level of financial development is characterized by heterogeneity

H3. Innovative city construction enhances financial development by promoting the development of an advanced industrial structure, triggering a concentration of scientific and technological talent, improving the quality of foreign investment, and strengthening the government's ability to govern

\section{Research Design}

\subsection{Model Design}

3.1.1. Baseline Model. China has established 59 pilot innovative cities from 2008 to 2013. In this article, we use the pilot innovative city policy as a proxy variable for innovative city construction, with pilot cities as the experimental group and nonpilot cities as the control group. Since it is difficult to avoid endogeneity problems caused by omitted variables in traditional regression models, and since the pilot policy of innovative cities in China is carried out gradually, a multiperiod DID model is constructed to examine the impact of innovative city construction on the level of urban financial development:

$$
\text { finance }_{i t}=\alpha_{0}+\alpha_{1} \text { test }_{i t}+\sum \lambda_{i t} \operatorname{control}_{i t}+\mu_{i}+\tau_{t}+\varepsilon_{i t} .
$$

In equation (1), finance ${ }_{i t}$ denotes the level of financial development of the city; test ${ }_{i t}$ denotes innovative city pilot policy, 1 in the pilot year and beyond, 0 otherwise, $\alpha_{1}$ coefficient reflects the effect of innovative city pilot policy; control $_{i t}$ denotes a series of control variables; $\mu_{i}, \tau_{t}$ denote city and time fixed effects, respectively; and $\varepsilon_{i t}$ denotes the random error term. 


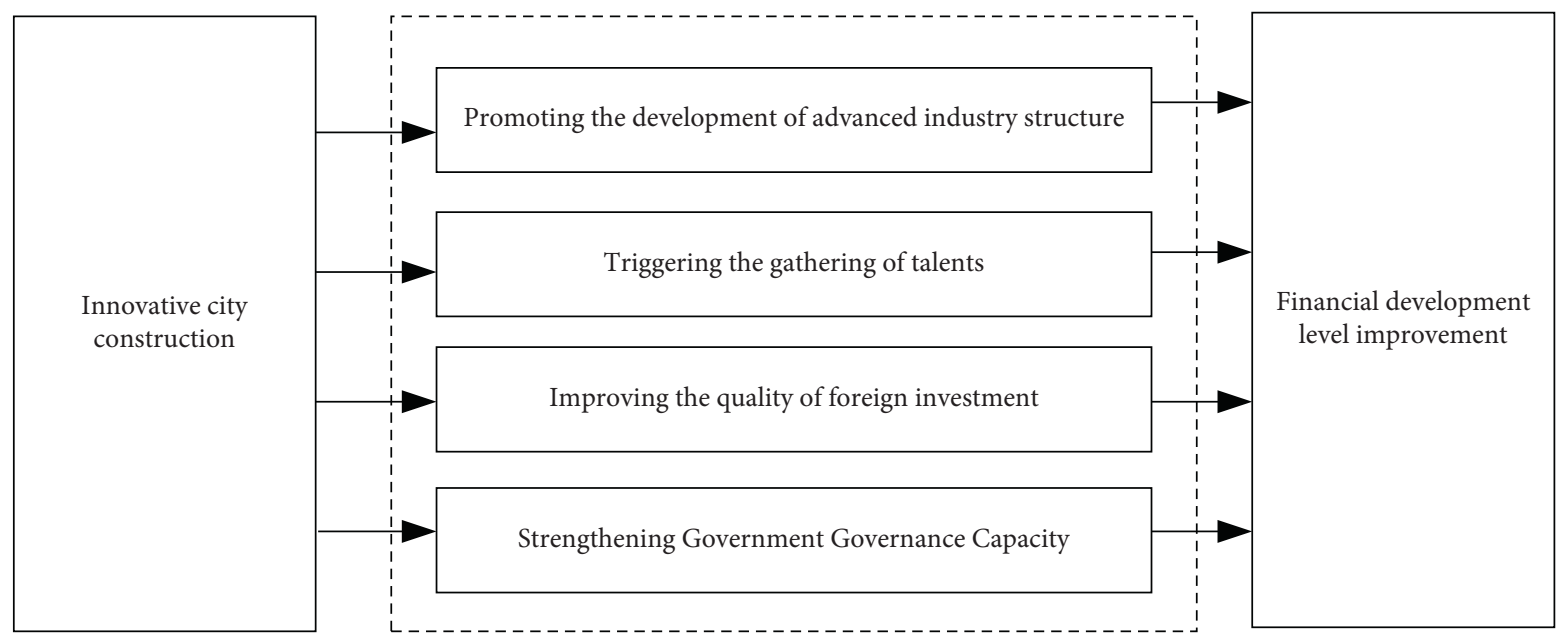

FiguRE 1: Mechanism of action.

3.1.2. Parallel Trend Test. When using the DID model, the basic premise needs to be satisfied that there is a common trend in the level of financial development between the experimental and control group of cities prior to the pilot. Therefore, the following parallel trend test model is set up in this article with reference to the findings of Beck et al. [13]:

$$
\begin{aligned}
\text { finance }_{i t}= & \alpha_{0}+\alpha_{1} \text { test }_{i, t-3}+\alpha_{2} \text { test }_{i, t-2} \\
& +\cdots+\alpha_{8} \text { test }_{i, t+4}+\mu_{i}+\tau_{t}+\varepsilon_{i t} .
\end{aligned}
$$

In equation (2), test ${ }_{i t}$ continues to denote the policy variable. As the only pilot city for innovative cities in 2008 was Shenzhen, the implementation time was set at 2009 for the parallel trend test, and the first three years and the last four years of the pilot were selected as the test interval, where $t-3$ denotes the third year before the pilot and analogously $t+4$ is the fourth year after the pilot. If the prepilot regression coefficient is insignificant and the postpilot significant, the parallel trend test is considered to be passed and a double difference model can be constructed.

3.1.3. Mechanism Analysis. If the results of the benchmark regression prove that innovative city construction significantly enhances urban financial development, an extended question is "Through which channels does innovative city construction promote financial development (i.e., hypothesis H3 in the previous section)?" In this article, we test hypothesis H3 with the help of the "three-step approach," a mediating effect idea [14]. In the first step, the policy variable is regressed on the level of financial development, and if the regression coefficient is significant, it proves that the innovative city construction has contributed to the improvement of the financial level. In the second step, the policy variable is regressed on the mediating variable $\left(z j_{i t}\right)$. And if the coefficient is significant, it proves that innovative city construction can significantly promote the development of advanced industrial structure (or trigger a concentration of scientific and technological talent, improve the quality of foreign investment, and enhance government governance capacity). In the third step, the policy variable and the mediating variable are put into the model at the same time to regress, and if the mediating variable is significant and the policy variable is significantly lower, then the existence of incomplete mediation effect is proved. This article constructs a mediating effects model as follows:

$$
\begin{gathered}
\text { finance }_{i t}=\alpha_{0}+\alpha_{1} \text { test }_{i t}+\sum \lambda_{i t} \operatorname{control}_{i t}+\mu_{i}+\tau_{t}+\varepsilon_{i t}, \\
z j_{i t}=\alpha_{0}+\alpha_{1} \text { test }_{i t}+\sum \lambda_{i t} \operatorname{control}_{i t}+\mu_{i}+\tau_{t}+\varepsilon_{i t}, \\
\text { finance }_{i t}=\alpha_{0}+\alpha_{1} \text { test }_{i t}+\alpha_{2} z j_{i t}+\sum \lambda_{i t} \operatorname{control}_{i t}+\mu_{i}+\tau_{t}+\varepsilon_{i t} .
\end{gathered}
$$

\subsection{Variables and Data}

3.2.1. Study Subjects. According to Zhang, this article selects the prefecture-level cities in China from 2005 to 2017 as the sample range [6]. Since 2008, several batches of pilot innovative cities have been launched in China. Considering the scope of the sample and the lag of the policy effect, this article selects five batches of pilot cities between 2008 and 2013, a total of 59 pilot cities for the study. As some of the data were missing, some of the cities with missing values were excluded and 59 pilot cities from the remaining cities in the sample were included in the experimental group, while the remaining 176 nonpilot cities were included in the control group.

\subsubsection{Variable Description}

(1) Explained Variables. This paper investigates the impact of innovative city construction on the level of financial development in cities. The explanatory variable is the level of financial development (finance); according to the study of Shi and Zhang, three variables were selected to describe the year-end balance of all loans of financial institutions in RMB (load), the year-end balance of all deposits of financial 
institutions in RMB (depo), and the number of people employed in the financial sector (finjob) [15]. Among them, the year-end balance of all loans of financial institutions in RMB (load) is used to refer to the degree of financial deepening; the year-end balance of all deposits of financial institutions in RMB (depo) is used to reflect the scale of financial sector development in the city.

The number of people employed in the financial sector (finjob) can be used as an indicator of the competitiveness of the financial industry $[14,16,17]$.

(2) Explanatory Variable. The core explanatory variable in this article is whether the city is an innovation city pilot city (test), which refers to the net effect of the innovation city pilot policy (hsr).

(3) Control Variables. In this article, based on the studies of Liang and Zhang, Golicice et al., Ma and Zhang, the following control variables were selected [18-20]: Gross regional product refers to the level of economic development of the city (gdp); total population at the end of the year refers to the size of the city (pop); actual foreign investment refers to the level of opening up to the outside world (fdi); the number of general undergraduate and tertiary students refers to the level of human capital (rlzb); expenditure on science and technology in the municipal area refers to the level of scientific and technological innovation (tech); the number of Internet broadband access users refers to the level of information technology (intel); and the share of tertiary industry in the GDP of the municipal area refers to the level of industrial structure (inds).

(4) Mediation Variables. Based on the research of Hospers [7], Liang and Zhang [18], and Zheng and Yang [21], the intermediary variables selected in this paper include the following four indicators: the number of employees in the scientific research comprehensive technical service industry in the municipal area refers to the degree of scientific and technological talent agglomeration (techjob). The actual amount of foreign investment (USD 10000)/foreign-invested enterprises above designated size refers to the quality of foreign investment. The proportion of tertiary industry in GDP (\%)/the proportion of secondary industry in GDP (\%) refers to the upgrading of industrial structure. Science and technology expenditure of municipal district (10000 yuan)/ local general public budget expenditure of municipal district (10000 yuan) refers to the governance capacity of the government.

The above variables are from China Urban Statistical Yearbook, iFind database, and Guotai'an database. In order to facilitate the construction of the model, some variables are logarithmicized in this paper, as shown in Table 1.

\section{Empirical Results Analysis}

4.1. Parallel Trend Test. In this article, the Indepo is used as the explanatory variables for parallel trend testing. The test results are shown in Figure 2. The results show that the policy coefficients were not significantly positive in all years
TABLE 1: Descriptive statistics of the variables.

\begin{tabular}{lcccccc}
\hline Variable & Unit & Obs & Mean & Std. dev & Min & Max \\
\hline Lndepo & 10000 & 3,055 & 16.09 & 1.135 & 13.58 & 20.26 \\
Lnload & 10000 & 3,055 & 16.25 & 1.293 & 12.84 & 21.05 \\
Lnfinjob & 1 & 3,055 & 9.401 & 0.819 & 7.003 & 13.2 \\
hsr & 1 & 3,055 & 0.103 & 0.305 & 0 & 1 \\
Lngdp & 10000 & 3,055 & 16.2 & 0.966 & 13.31 & 19.55 \\
Lnpop & 10000 & 3,055 & 5.97 & 0.638 & 3.935 & 9.314 \\
Lnfdi & 10000 & 3,055 & 10.03 & 1.723 & 1.098 & 14.94 \\
Lnrlzb & 1 & 3,055 & 10.53 & 1.259 & 5.793 & 13.91 \\
Lntech & 10000 & 3,055 & 12.58 & 0.972 & 9.65 & 16.07 \\
Lnintel & 10000 & 3,055 & 3.617 & -1.11 & 3.744 & 8.551 \\
Inds & $1 \%$ & 3,055 & 43.49 & 10.91 & 12.23 & 80.56 \\
Lntechjob & 1 & 3,055 & 7.919 & 1.285 & 4.605 & 13.47 \\
Lnfdiqty & 10000 & 3,055 & 6.59 & -1.47 & 0.405 & 13.3 \\
gjh & 10000 & 3,055 & 0.982 & 0.57 & 0.141 & 5.34 \\
Gov & $1 \%$ & 3,055 & 0.184 & 0.044 & 0.014 & 0.497 \\
\hline
\end{tabular}

before the implementation of the pilot policy, while the policy coefficients were significantly positive in all years after the implementation of the pilot policy, indicating that the effect of the pilot innovative city on the enhancement of the level of urban financial development has been initially verified, and the policy effect starts to appear in the first year of implementation.

4.2. Baseline Regression. The results of the baseline regression are shown in Table 2, where columns (1) to (3) are the regression results without control variables. The results show that the coefficient of the policy effect (hereafter hsr) is significantly positive at the $1 \%$ level, regardless of whether the explanatory variables are Indepo, Inload, and lnfinjob, and the hypothesis H1 holds. Columns (4) to (6) show the results of the regressions with the inclusion of control variables. The results show that the coefficient of hsr is still significant at the $1 \%$ level after the inclusion of control variables, which indicates that innovative city construction can effectively improve the level of urban financial development. Meanwhile, observing the $R^{2}$ of the goodness of fit, it can be found that the $R^{2}$ of columns (4) to (6) all improve after the inclusion of control variables, indicating that each control variable selected in this article is more reasonable.

For the regression results of the control variables, we can observe the regression results of columns (4) to (6) to find that the level of urban economic development, city size, and the level of science and technology innovation all significantly and positively influence the level of financial development of cities to improve, indicating that the financial industry, as a high-end factor market, depends on the city's economic condition for its development, while the city's science and technology innovation also provides good science and technology services for financial development and helps the financial industry to develop. The level of external openness, the level of human capital, the level of informatization, and the level of industrial structure are not significant or show opposite significant results. The possible reasons for this are that for 


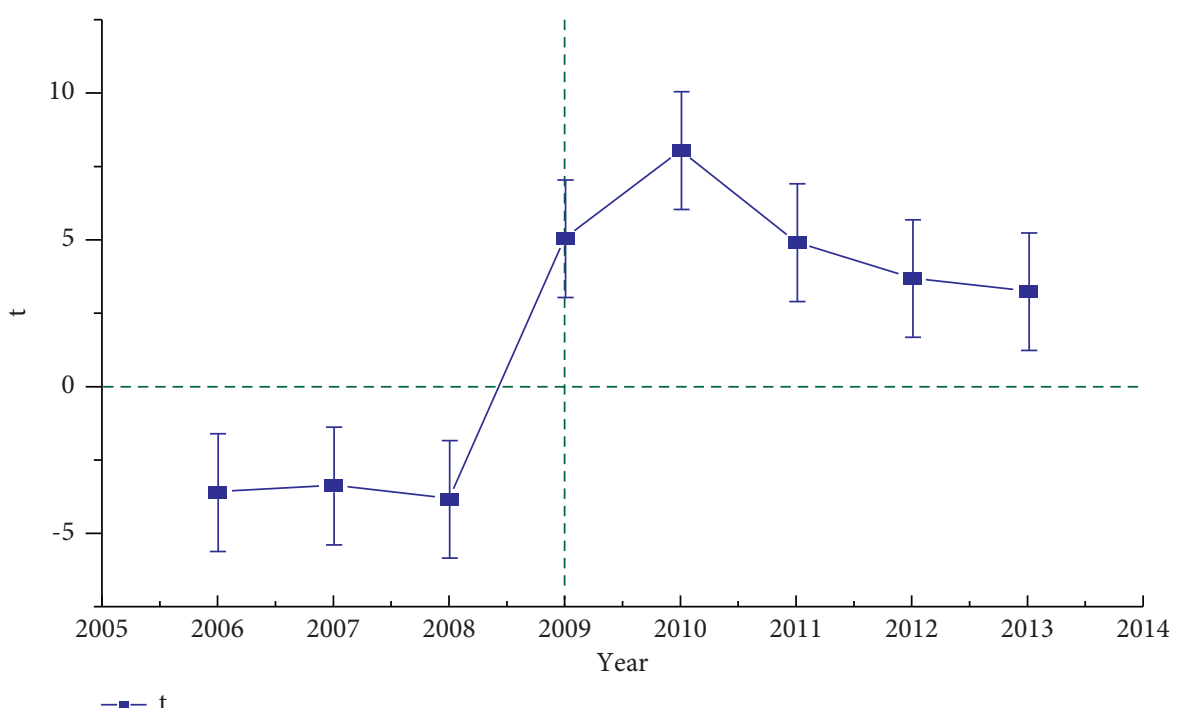

Figure 2: Parallel trend check chart.

TABLE 2: Estimated results of the baseline regression.

\begin{tabular}{|c|c|c|c|c|c|c|}
\hline & $\begin{array}{c}(1) \\
\text { lndepo }\end{array}$ & $\begin{array}{c}(2) \\
\text { lnload }\end{array}$ & $\begin{array}{c}(3) \\
\text { lnfinjob }\end{array}$ & $\begin{array}{c}(4) \\
\text { lndepo }\end{array}$ & $\begin{array}{c}(5) \\
\text { lnload }\end{array}$ & $\begin{array}{c}(6) \\
\operatorname{lnfinjob}\end{array}$ \\
\hline hsr & $\begin{array}{c}0.1085^{* * *} \\
(2.97) \\
\end{array}$ & $\begin{array}{c}0.1431^{* * *} \\
(4.32) \\
\end{array}$ & $\begin{array}{c}0.1103^{* * *} \\
(3.58) \\
\end{array}$ & $\begin{array}{c}0.1020^{* * *} \\
(3.18) \\
\end{array}$ & $\begin{array}{c}0.1164^{* * *} \\
(3.74) \\
\end{array}$ & $\begin{array}{c}0.0981^{* * *} \\
(3.31) \\
\end{array}$ \\
\hline Lngdp & & & & $\begin{array}{c}0.2200^{* * *} \\
(6.70)\end{array}$ & $\begin{array}{c}0.0549^{*} \\
(1.70)\end{array}$ & $\begin{array}{c}0.1037^{* *} \\
(2.47) \\
\end{array}$ \\
\hline Lnpop & & & & $\begin{array}{c}0.0396^{* *} \\
(2.33) \\
\end{array}$ & $\begin{array}{l}0.0127 \\
(1.25) \\
\end{array}$ & $\begin{array}{c}0.0681^{* * *} \\
(3.13)\end{array}$ \\
\hline $\operatorname{lnfdi}$ & & & & $\begin{array}{c}0.0187^{* * *} \\
(2.80)\end{array}$ & $\begin{array}{c}0.0024 \\
(0.51) \\
\end{array}$ & $\begin{array}{c}-0.0115^{* *} \\
(-2.00)\end{array}$ \\
\hline Lnrlzb & & & & $\begin{array}{c}0.0538^{* *} \\
(1.97) \\
\end{array}$ & $\begin{array}{c}-0.0234 \\
(-0.77)\end{array}$ & $\begin{array}{c}0.0023 \\
(0.09) \\
\end{array}$ \\
\hline Lntech & & & & $\begin{array}{c}0.1462^{* * *} \\
(4.58)\end{array}$ & $\begin{array}{c}0.1305^{* * *} \\
(3.91) \\
\end{array}$ & $\begin{array}{c}0.0566^{*} \\
(1.93)\end{array}$ \\
\hline lnintel & & & & $\begin{array}{c}0.0034 \\
(0.24) \\
\end{array}$ & $\begin{array}{c}0.0669^{* * *} \\
(3.13)\end{array}$ & $\begin{array}{c}-0.0095 \\
(-0.71)\end{array}$ \\
\hline Inds & & & & $\begin{array}{c}0.0006 \\
(0.37) \\
\end{array}$ & $\begin{array}{c}-0.0018 \\
(-1.11) \\
\end{array}$ & $\begin{array}{c}0.0005 \\
(0.35) \\
\end{array}$ \\
\hline _cons & $\begin{array}{c}15.4532^{* * *} \\
(910.55) \\
\end{array}$ & $\begin{array}{c}14.9535^{* * *} \\
(1172.54) \\
\end{array}$ & $\begin{array}{c}9.1552^{* * *} \\
(797.51) \\
\end{array}$ & $\begin{array}{c}9.4362^{* * *} \\
(12.11)\end{array}$ & $\begin{array}{c}12.6854^{* * *} \\
(16.23) \\
\end{array}$ & $\begin{array}{c}6.6013^{* * *} \\
(7.25)\end{array}$ \\
\hline City-fixed & Yes & Yes & Yes & Yes & Yes & Yes \\
\hline Year-fixed & Yes & Yes & Yes & Yes & Yes & Yes \\
\hline$N$ & 3055 & 3055 & 3055 & 3055 & 3055 & 3055 \\
\hline$R^{2}$ & 0.8303 & 0.9675 & 0.5599 & 0.8512 & 0.9698 & 0.5608 \\
\hline
\end{tabular}

Note. $T$ statistics are in parentheses. ${ }^{*} p<0.10,{ }^{* *} p<0.05$, and ${ }^{* * *} p<0.01$.

universities in cities, they have overexpanded the scale of their intake at the expense of the quality of education and are unable to provide a good human capital base for urban financial development; at the same time, local governments have overemphasised the quantity of foreign investment brought in at the expense of the quality of foreign investment, leading to a large inflow of low-quality foreign investment and creating a certain competitive, predatory effect on the local industry, to the detriment of the development of the city's financial sector.
4.3. Robustness Tests. The level of financial development may not only be influenced by the construction of innovative cities, but also by other related policies, which may lead to some errors in the regression results. Since the sample time of this article is 2005-2017, after retrieving other relevant policies in the sample time, this article includes the carbon emission trading pilot policy (ETS) and the air pollution prevention action plan (APP) into the robustness consideration of this article, and robustness tests are conducted by adding the dummy variables of these two policies separately 
TABLE 3: Robustness tests.

\begin{tabular}{|c|c|c|c|c|c|c|c|c|c|}
\hline & $\begin{array}{c}(1) \\
\text { lndepo }\end{array}$ & $\begin{array}{c}(2) \\
\text { lnload }\end{array}$ & $\begin{array}{c}(3) \\
\text { lnfinjob }\end{array}$ & $\begin{array}{c}(4) \\
\text { lndepo }\end{array}$ & $\begin{array}{c}(5) \\
\text { lnload }\end{array}$ & $\begin{array}{c}(6) \\
\text { lnfinjob }\end{array}$ & $\begin{array}{c}(7) \\
\text { lndepo }\end{array}$ & $\begin{array}{c}(8) \\
\text { lnload }\end{array}$ & $\begin{array}{c}(9) \\
\text { lnfinjob }\end{array}$ \\
\hline hsr & $\begin{array}{c}0.104^{* * *} \\
(3.41)\end{array}$ & $\begin{array}{c}0.117^{* * *} \\
(3.73)\end{array}$ & $\begin{array}{c}0.0987^{* * *} \\
(3.34)\end{array}$ & $\begin{array}{c}0.0961^{* *} \\
(2.98)\end{array}$ & $\begin{array}{c}0.113^{* * *} \\
(3.61)\end{array}$ & $\begin{array}{c}0.0830^{* *} \\
(2.77)\end{array}$ & $\begin{array}{c}0.1154^{* * *} \\
\quad(3.76)\end{array}$ & $\begin{array}{c}0.0993^{* * *} \\
(3.20)\end{array}$ & $\begin{array}{c}0.1032^{* * *} \\
\quad(3.41)\end{array}$ \\
\hline Ets & $\begin{array}{c}-0.147^{* * *} \\
(-4.19)\end{array}$ & $\begin{array}{c}0.0495 \\
(1.96)\end{array}$ & $\begin{array}{l}-0.034 \\
(-1.01)\end{array}$ & & & & & & \\
\hline App & & & & $\begin{array}{c}0.0408 \\
-1.64 \\
\end{array}$ & $\begin{array}{c}-0.0211 \\
(-0.88) \\
\end{array}$ & $\begin{array}{c}0.103^{* * *} \\
(3.83)\end{array}$ & & & \\
\hline Control & Yes & Yes & Yes & Yes & Yes & Yes & Yes & Yes & Yes \\
\hline City-fixed & Yes & Yes & Yes & Yes & Yes & Yes & Yes & Yes & Yes \\
\hline Year-fixed & Yes & Yes & Yes & Yes & Yes & Yes & Yes & Yes & Yes \\
\hline$N$ & 3055 & 3055 & 3055 & 3055 & 3055 & 3055 & 3055 & 3055 & 3055 \\
\hline$R^{2}$ & 0.8541 & 0.9699 & 0.5615 & 0.8515 & 0.9698 & 0.5700 & 0.8498 & 0.9697 & 0.5568 \\
\hline
\end{tabular}

Note. $T$ statistics are in parentheses. ${ }^{*} p<0.10,{ }^{* *} p<0.05$, and ${ }^{* * *} p<0.01$.

for re-regression. In addition, considering the lagged effect of the innovative city pilot policy and the interference of sample outliers, this article follows Cheng et al. [22] and uses the tailing method (i.e., tailing the highest and lowest 2\% samples of the explanatory and control variables) for robustness testing.

The results of the robustness test are shown in Table 3. Columns (1) to (3) are the results of the regression after adding the dummy variable for the carbon trading pilot policy, columns (4) to (6) are the results of the regression after adding the dummy variable for the air pollution prevention action plan, and columns (7) to (9) are the results of the regression after tailoring. It can be found that the coefficient of the policy variable hsr remains significantly positive in all regressions, which indicates that the result that innovative city construction helps to improve the level of urban financial development is robust; that is, this study passes the robustness test.

4.4. Placebo Test. For the DID model, there may be differences in the characteristics of the treatment and control groups other than policy factors. Although equation (1) can control most of the city characteristics variables, it is not sufficient to control all city characteristics. In this article, we refer to the study of $\mathrm{Li}$ et al. and conduct a placebo test with lnfinjob as the explained variable to observe whether possible omitted characteristics have an impact on the empirical results [23].

$$
\alpha_{1 r}=\alpha_{1}+\delta * \frac{\operatorname{cov}\left(\text { test }_{i t}, \vartheta_{i t} \mid D\right)}{\operatorname{var}\left(\text { test }_{i t}, D\right)} .
$$

First, we derive the expression for the hsr coefficient according to equation (1) (see equation (6)). If a variable can be found to replace hsr and this variable does not theoretically affect the corresponding $\operatorname{lnfdijob}$ (i.e., $\alpha_{1}=0$ ), after estimating $\alpha_{1 r}=0$, it can be shown that $\delta=0$; that is, the omitted feature does not affect the regression results. Therefore, in this article, the innovative city construction is randomized, and the regression is repeated 1000 times so that lnfdijob is not affected (i.e., $\alpha_{1 r}^{\text {random }}=0$ ). We compiled the results of the regression in Figure 3.

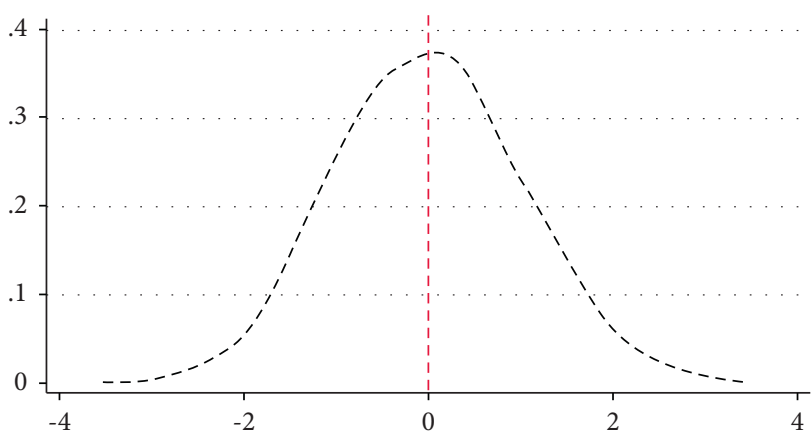

Kernel $=$ epanechnikov, bandwidth $=0.2299$

Figure 3: Placebo test results.

As shown in Figure 3, after 1000 regressions, $\alpha_{1 r}^{\text {random }}$ are all around 0 and normally distributed, respectively, which indicates that this article passes the placebo test, and the results are robust.

\section{Further Analysis}

5.1. Heterogeneity Analysis. The findings of the previous study suggest that innovative city building can generally contribute to a higher level of financial development in cities. However, for China, there are significant differences in resource advantages and economic levels between cities belonging to different geographical locations. Is there a different impact of innovative city building on financial sector development due to geographical differences (i.e., hypothesis H2)? This article will further discuss the regional heterogeneity of pilot policies for innovative cities.

Table 4 shows the heterogeneity regression results for the eastern, central, and western cities according to the geographical location of China.

Among them, columns (1) to (3) are the regression results for the subsample of eastern cities, columns (4) to (6) are the regression results for the subsample of central cities, and columns (7) to (9) are the regression results for the subsample of western cities. From Table 4, it can be seen that the construction of innovative cities significantly improves the level of financial development of cities in central China, 
TABLE 4: Heterogeneity tests.

\begin{tabular}{|c|c|c|c|c|c|c|c|c|c|}
\hline & $\begin{array}{c}(1) \\
\text { lndepo }\end{array}$ & $\begin{array}{c}(2) \\
\text { lnload }\end{array}$ & $\begin{array}{c}(3) \\
\ln f i n j o b\end{array}$ & $\begin{array}{c}(4) \\
\text { lndepo }\end{array}$ & $\begin{array}{c}(5) \\
\text { lnload }\end{array}$ & $\begin{array}{c}(6) \\
\text { lnfinjob }\end{array}$ & $\begin{array}{c}(7) \\
\text { lndepo }\end{array}$ & $\begin{array}{c}(8) \\
\text { lnload }\end{array}$ & $\begin{array}{c}(9) \\
\text { lnfinjob }\end{array}$ \\
\hline hsr & $\begin{array}{l}0.0199 \\
(0.55) \\
\end{array}$ & $\begin{array}{c}0.1112^{* * *} \\
(3.02) \\
\end{array}$ & $\begin{array}{c}0.0572 \\
(1.65) \\
\end{array}$ & $\begin{array}{c}0.1487^{* * *} \\
(3.55) \\
\end{array}$ & $\begin{array}{c}0.1463^{* * *} \\
(2.77) \\
\end{array}$ & $\begin{array}{c}0.1676^{* *} \\
(2.40) \\
\end{array}$ & $\begin{array}{c}0.1830 \\
(1.56) \\
\end{array}$ & $\begin{array}{c}0.0104 \\
(0.11) \\
\end{array}$ & $\begin{array}{c}-0.0169 \\
(-0.25)\end{array}$ \\
\hline _cons & $\begin{array}{c}10.1003^{* * *} \\
(8.98) \\
\end{array}$ & $\begin{array}{c}11.8722^{* * *} \\
(7.83) \\
\end{array}$ & $\begin{array}{c}5.7955^{* * *} \\
(3.01) \\
\end{array}$ & $\begin{array}{c}7.2663^{* * *} \\
(5.44) \\
\end{array}$ & $\begin{array}{c}13.3720^{* * *} \\
(16.57) \\
\end{array}$ & $\begin{array}{c}5.9121^{* * *} \\
(5.71) \\
\end{array}$ & $\begin{array}{c}5.0724^{* *} \\
(2.10)\end{array}$ & $\begin{array}{c}14.2167^{* * *} \\
(6.13) \\
\end{array}$ & $\begin{array}{c}4.6238 \\
(1.66) \\
\end{array}$ \\
\hline Control & Yes & Yes & Yes & Yes & Yes & Yes & Yes & Yes & Yes \\
\hline City-fixed & Yes & Yes & Yes & Yes & Yes & Yes & Yes & Yes & Yes \\
\hline Year-fixed & Yes & Yes & Yes & Yes & Yes & Yes & Yes & Yes & Yes \\
\hline$R^{2}$ & 0.8539 & 0.9696 & 0.6340 & 0.8595 & 0.9756 & 0.4822 & 0.8980 & 0.9725 & 0.6102 \\
\hline
\end{tabular}

Note. $T$ statistics are in parentheses. ${ }^{*} p<0.10,{ }^{* *} p<0.05$, and ${ }^{* * *} p<0.01$.

while it does not significantly improve the level of financial development of cities in the east and west of China, proving hypothesis $\mathrm{H} 2$. The possible reason for this is that, compared to eastern and central cities, western cities have obvious disadvantages in terms of economic development level and technological innovation, resulting in a weaker marginal effect of innovative city building on promoting the development of the financial sector in the western region. As for the eastern cities of China, although the economic development level and innovation capacity of the eastern cities of China have obvious advantages over the central and western cities, however, the fierce competition among cities in the eastern region, with greater local protection and competition for talent resources, has to a certain extent inhibited the spillover effect of innovative city building and thus prevented the positive spillover effect on the improvement of financial development.

5.2. Mechanism Analysis. Based on the previous analysis of the influence mechanism on the enhancement of financial development level, this article examines the transmission path (i.e., hypothesis H3) of innovative city construction affecting the enhancement of city financial development level in four dimensions: advanced development of industrial structure, triggering the concentration of scientific and technological talents, improving the quality of foreign investment, and strengthening government governance capacity. The number of people employed in the financial sector (hereafter referred to as finjob) was used as a proxy variable for the level of financial development in the mechanism analysis, and the four mediating variables were sequentially included in equations (3) to (5) for regression, and the regression results are shown in Table 5.

Columns (1) to (2) examine the mediating effect of the concentration of science and technology talent (hereafter referred to as techjob). The regression coefficient of the policy effect in column (1) is 0.1813 and is significantly positive at the $1 \%$ level, indicating that innovative city construction has effectively increased the concentration of scientific and technological talents. It may be that innovative cities are tilted towards innovation in terms of finance and taxation, giving more encouragement and support to scientific and technology talents in terms of policy, promoting scientific and technology innovation and thus increasing the concentration of scientific and technology talents. In column (2), the coefficients of hsr and techjob are 0.0801 and 0.066 , respectively, both of which are positive at the $1 \%$ level, indicating that the mechanism that innovative city construction improves the concentration of science and technology talents in the pilot cities and hence the level of financial development in the cities has been verified.

Columns (3) to (4) test the mediating effect of foreign investment quality (hereafter referred to as fdiqty). Among them, the coefficient of hsr regression in column (3) is not significant, indicating that innovative city construction cannot significantly improve the quality of foreign investment, which is consistent with the results of the previous analysis. The coefficients of fdiqty and hsr in column (4) are 0.0185 and 0.0908 , respectively, and both are significantly positive at the $1 \%$ level, indicating that the improved quality of foreign investment is a fully mediating variable in enhancing the level of financial development in cities. Therefore, in foreign investment, local governments should change the notion of focusing on quantity rather than quality and increase their efforts to attract quality foreign investment inflows in order to improve the level of financial development in cities.

Columns (5) to (6) test the mediating effect of the advanced industrial structure (hereafter referred to as gjh). The regression coefficient of hsr in column (5) is 0.0487 and is significant at the $1 \%$ level, indicating that innovative city construction promotes the development of advanced industry structure. It is possible that the implementation of the pilot policy of innovative cities will help the pilot cities to achieve significant results in human capital and technology innovation and thus promote the development of advanced industry structure. Meanwhile, the coefficients of gjh and hsr in column (6) are 0.1046 and 0.0931 , respectively, both of which are significantly positive at the $1 \%$ level; this indicates the existence of a strong intermediary effect, which shows that the development of advanced urban industry structure is the mechanism that innovative city construction affects the level of urban financial development. That also indicates that innovative city construction does enhance the level of urban financial development by promoting the development of advanced industrial structure in cities.

Columns (7) to (8) test the mediating effect of government governance capacity (hereafter referred to as gov). It can be found that although the regression coefficient of hsr 
TABLE 5: Intermediary effect tests.

\begin{tabular}{|c|c|c|c|c|c|c|c|c|}
\hline & $\begin{array}{c}(1) \\
\text { lntechjob }\end{array}$ & $\begin{array}{c}(2) \\
\text { lnfinjob }\end{array}$ & $\begin{array}{c}(3) \\
\text { lnfdiqty }\end{array}$ & $\begin{array}{c}(4) \\
\ln f i n j o b\end{array}$ & $\begin{array}{l}\text { (5) } \\
\text { gjh }\end{array}$ & $\begin{array}{c}(6) \\
\text { lnfinjob }\end{array}$ & $\begin{array}{l}(7) \\
\text { Gov }\end{array}$ & $\begin{array}{c}(8) \\
\text { lnfinjob }\end{array}$ \\
\hline hsr & $\begin{array}{c}0.1813^{* * *} \\
(3.94) \\
\end{array}$ & $\begin{array}{c}0.0801^{* * *} \\
(2.75) \\
\end{array}$ & $\begin{array}{c}0.0947 \\
(1.44) \\
\end{array}$ & $\begin{array}{c}0.0908^{* * *} \\
(3.11) \\
\end{array}$ & $\begin{array}{c}0.0487^{* * *} \\
(3.47) \\
\end{array}$ & $\begin{array}{c}0.0931^{* * *} \\
(5.85) \\
\end{array}$ & $\begin{array}{c}0.0117^{* * *} \\
(3.69) \\
\end{array}$ & $\begin{array}{c}0.1011^{* * *} \\
(3.35) \\
\end{array}$ \\
\hline lntechjob & & $\begin{array}{c}0.0660^{* * *} \\
(3.89)\end{array}$ & & & & & & \\
\hline lnfdiqty & & & & $\begin{array}{c}0.0185^{* * *} \\
(3.00)\end{array}$ & & & & \\
\hline gjh & & & & & & $\begin{array}{c}0.1046^{* * *} \\
(4.83) \\
\end{array}$ & & \\
\hline gov & & & & & & & & $\begin{array}{c}-0.2455 \\
(-1.06) \\
\end{array}$ \\
\hline _cons & $\begin{array}{c}4.0342^{* * *} \\
(3.77)\end{array}$ & $\begin{array}{c}6.5172^{* * *} \\
(6.89) \\
\end{array}$ & $\begin{array}{l}1.0301 \\
(0.53) \\
\end{array}$ & $\begin{array}{c}6.9003^{* * *} \\
(6.94)\end{array}$ & $\begin{array}{c}-1.1594^{* * *} \\
(-3.62) \\
\end{array}$ & $\begin{array}{c}6.7236^{* * *} \\
(18.42) \\
\end{array}$ & $\begin{array}{c}-0.4988^{* * *} \\
(-5.46) \\
\end{array}$ & $\begin{array}{c}6.4772^{* * *} \\
(7.10)\end{array}$ \\
\hline Control & Yes & Yes & Yes & Yes & Yes & Yes & Yes & Yes \\
\hline City-fixed & Yes & Yes & Yes & Yes & Yes & Yes & Yes & Yes \\
\hline Year-fixed & Yes & Yes & Yes & Yes & Yes & Yes & Yes & Yes \\
\hline$N$ & 3055 & 3055 & 3055 & 3055 & 3055 & 3055 & 3055 & 3055 \\
\hline$R^{2}$ & 0.2826 & 0.5619 & 0.7153 & 0.5591 & 0.7319 & 0.5644 & 0.3982 & 0.5612 \\
\hline
\end{tabular}

Note. $T$ statistics are in parentheses. ${ }^{*} p<0.10,{ }^{* *} p<0.05$, and ${ }^{* * *} p<0.01$.

in column (7) is significantly positive at $1 \%$, with a coefficient value of 0.0117 , indicating that innovative city construction improves the government's governance capacity, gov is not significant after adding gov and policy effects together in the model regression, proving that innovative city construction does not improve the level of urban financial development by improving the government's governance capacity.

Therefore, the mechanism analysis shows that the innovative city construction enhances urban financial development mainly by increasing the concentration of scientific and technological talents in the pilot cities and by promoting the advanced development of the city's industry structure, which verifies the previous theoretical mechanism analysis.

\section{Conclusions and Recommendations}

This article empirically investigates the impact of innovative city construction on the level of financial development using the DID method based on panel data of 235 cities in China from 2005 to 2017. The study shows that the construction of innovative cities significantly improves the level of financial development, and the results still hold after several robustness tests. Further heterogeneity analysis and intermediary effect analysis reveal that the effect of innovative city construction on financial development is most pronounced in central cities of China, and the financial development level is enhanced through two intermediary paths: increasing the concentration of scientific and technological talents and promoting the advanced industrial structure.

Based on the above findings, this article makes the following policy recommendations. Firstly, China should expand the scope of innovative cities in an orderly manner on the basis of the experience of pilot innovative cities. The findings of this article and previous studies show that innovative cities can enhance financial development, promote the upgrading of industrial structures, and lead enterprises to continuous innovation. Therefore, China should further improve the proliferation practice of "local pilot-central summary-local promotion," and according to the location characteristics of different cities, specify specific development directions, establish regulatory mechanisms, and expand the scope of pilot projects.

Secondly, it explores the multidimensional path of innovative city construction to enhance the level of financial development and promotes the high-quality development of the financial industry through multiple initiatives. The research shows that the construction of innovative cities can promote the upgrading of financial development through the promotion of advanced industrial structure and the concentration of talents. Therefore, local governments should strengthen guidance and coordination, introduce corresponding policies to encourage cooperation between research institutions and high-tech enterprises, stimulate the multidirectional flow of high-end talents, capital, and other innovation factors, introduce preferential policies for scientific and technological innovation talents, and expand the comparative advantages of industries, thus promoting the upgrading of the level of financial development in cities.

Thirdly, the construction of innovative cities should advocate diversified development strategies and avoid homogenisation. This article shows that there is regional heterogeneity in China's innovative city pilot policies, with differentiated characteristics in the effects on the level of financial development of cities in different geographical locations.

Therefore, the central government should continue to promote pilot innovative cities and should build urban innovation systems according to local characteristics. At the same time, considering the higher development of the financial sector in eastern cities, it should deepen the role of innovative city construction in promoting financial 
development in central and western cities and focus on examining the concrete implementation of innovative city construction in central and western cities.

Fourth, enhance the status of technological innovation in the financial industry. After a number of robustness tests, the research shows that the construction of innovative cities helps to improve the level of urban financial development, and the result is stable. Therefore, financial institutions should take the opportunity of innovative city construction, actively learn, and use various information technology means to activate the power of financial technology innovation.

\section{Data Availability}

The processed data required to reproduce these findings cannot be shared at this time as the data also form part of an ongoing study.

\section{Conflicts of Interest}

The authors declare that they have no conflicts of interest.

\section{Authors' Contributions}

Z.Z. conceptualized the study; Y.Z. was responsible for data curation; Y.C. provided model; C.Y. was responsible for formal analysis; Z.H. prepared the original draft; and Z. Z. reviewed and edited the manuscript.

\section{Acknowledgments}

This work was financially supported by the National Social Science Fund of China (19FJYB043) and the Fujian Soft Science Research Program (2018R0048).

\section{References}

[1] G. Zhou, K. Gong, S. Luo, and G. Xu, "Inclusive finance, human capital and regional economic growth in China," Sustainability, vol. 10, no. 4, p. 1194, 2018.

[2] M. D. Bordo and P. L. Rousseau, "Legal-political factors and the historical evolution of the finance-growth link," European Review of Economic History, vol. 10, no. Pt3, pp. 421-444, 2006.

[3] J. Zeng, Y. Liu, R. Wang, and P. Zhan, “Absorptive capacity and regional innovation in China: an analysis of patent applications, 2000-2015," Applied Spatial Analysis and Policy, vol. 12, no. 4, pp. 1031-1049, 2019.

[4] C. Ye, Z. Zhao, and J. Cai, "The impact of smart city construction on the quality of foreign direct investment in China," Complexity, vol. 2021, Article ID 5619950, 9 pages, 2021.

[5] F. Alshubiri, S. Jamil, and M. Elheddad, "The impact of ICT on financial development: empirical evidence from the Gulf Cooperation Council countries," International Journal of Engineering Business Management, vol. 11, 2019.

[6] Y. Zhang, "Does the pilot policy of innovative city improve the level of scientific and technological talents gathering--quasi natural experiments from 240 prefecture level cities," Progress of Science and Technology and Countermeasure, vol. 38, no. 12, pp. 116-123, 2021.
[7] G. J. Hospers, "Governance in innovative cities and the importance of branding," Innovation: Management, Policy \& Practice, vol. 10, no. 2/3, pp. 224-234, 2018.

[8] C. Fang, H. Ma, Z. Wang, and G. Li, "The sustainable development of innovative cities in China: comprehensive assessment and future configuration," Journal of Geographical Sciences, vol. 24, pp. 1095-1114, 2014.

[9] S. Zhang, X. Wang, and B. Zhang, "The policy effects of innovative city pilot on the dual efficiency of industry-university-research knowledge flow," Technology Analysis \& Strategic Management, 2021.

[10] W. W. Guo and W. Q. Wang, "How do financial agglomeration and regional house prices affect industrial structure upgrading: two-wheel drive or two-way inhibition?" Journal of Capital University of Economics and Business, vol. 23, no. 1, pp. 24-37, 2021.

[11] A. Aibai, X. Huang, Y. Luo, and Y. Peng, "Foreign direct investment, institutional quality, and financial development along the belt and road: an empirical investigation," Emerging Markets Finance and Trade, vol. 55, no. 14, pp. 3275-3294, 2019.

[12] H. Li, J. Zhang, C. Wang, and Y. Wang, "An evaluation of the impact of environmental regulation on the efficiency of technology innovation using the combined DEA model: a case study of Xi'an, China," Sustainable Cities and Society, vol. 42, pp. 355-369, 2018.

[13] T. Beck, R. Levine, and A. Levkov, "Big bad banks? the winners and losers from bank deregulation in the United States," The Journal of Finance, vol. 65, no. 5, pp. 1637-1667, 2010.

[14] M. Mainelli, "Market of markets: the global financial centres index," The Journal of Risk Finance, vol. 8, pp. 313-319, 2007.

[15] Y. T. Shi and X. B. Zhang, "Does smart city building promote financial development?--A quasi-natural experimental study based on the establishment of smart cities," Journal of Financial Econometrics, vol. 12, pp. 82-88, 2019.

[16] C. Liu, G. Y. Cao, and G. R. Ma, "Are local government financing platforms squeezing out SME loans?" Economic Research, vol. 55, no. 3, pp. 50-64, 2020.

[17] W. D. Huo and F. H. Deng, "Financial development and cross-border trade RMB settlement-an empirical study based on inter-provincial panel data," International Trade Issues, vol. 8, pp. 145-155, 2015.

[18] J. S. Liang and Y. S. Zhang, "A study on the influencing factors of regional financial development in China," Macroeconomic Research, vol. 7, pp. 14-24+70, 2019.

[19] S. L. Golicic, J. H. Foggin, and J. T. Mentzer, "Relationship magnitude and its role in interorganizational relationship structure," Journal of Business Logistics, vol. 24, no. 1, pp. 57-75, 2011.

[20] Z. H. Ma and X. Zhang, "Can the construction of innovative cities promote the upgrading of urban industrial structure? --a "quasi-natural experiment" based on 286 prefecture-level cities in China," Journal of Tianjin University of Commerce, vol. 41, no. 2, pp. 3-14, 2021.

[21] L. Zheng and S. Yang, "Has the pilot innovative city improved the level of urban innovation?" The Journal of Economic Perspectives, vol. 8, pp. 70-85, 2019.

[22] J. Cheng, J. Yi, S. Dai, and Y. Xiong, "Can low-carbon city construction facilitate green growth? evidence from China's pilot low-carbon city initiative," Journal of Cleaner Production, vol. 231, no. 9, pp. 1158-1170, 2019.

[23] P. Li, Y. Lu, and J. Wang, "Does flattening government improve economic performance? evidence from China," Journal of Development Economics, vol. 123, pp. 18-37, 2016. 